\title{
Effect of transport measures and curfew against COVID-19 spread on air pollution (TSP) in Ecuador's three most populous cities
}

\section{Dama Research Center limited}

Address: 87-105 Chatham Road South, Tsim Sha Tsui, Kowloon, Hong Kong (Company registration number: 2875213) Correspondence: Regional Representative for Latin America and Caribbean, 202/B, San Francisco 300 bldg, Gral. Cordova 1015 Guayaquil 090313, Ecuador. Email: info@damaresearch.com, Tel: +593-968328767

Competing interests: Author(s) stated no compete of interest.

Grant information: This study was supported by Dama Research Center limited.

Acknowledgement: Authors are grateful to the international research network "Red Iberoamericana de Investigación en Gestión de Proyectos Sustentables e Innovación de los Procesos" for their collaboration.

Copyright 2020 (C) The Author(s). This is an Open Access article under the CC-BY 4.0 license published by Dama Research Center limited a private company limited by shares organized and existing under the laws of Hong Kong, with its head office located at Room 409, Beverley Commercial Centre, 87-105 Chatham Road South, Tsim Sha Tsui, Kowloon- Hong Kong and company number: 2875213.

How to cite: DRC. "Effect of transport measures and curfew against COVID-19 spread on air pollution (TSP) in Ecuador's three most populous cities." DRC Sustainable Future 2020, 1(1): 54-59, DOI: 10.37281/DRCSF/1.1.7

\begin{abstract}
Although the current situation poses challenges to foretelling the future consequences of coronavirus spread, we consider that environmental load-related research has become more important than ever before. Many experts believe that in the framework of increasingly dire public health emergency, policy and decision makers should facilitate COVID-19 outbreak to transitioning to sustainable consumption and production. With the purpose of evaluating the importance of sustainability efforts, here we describe the total suspended particulates (TSP), originating from traffic emissions, caused by air pollution in the three most populous cities of Ecuador. Compared are measurements taken prior to, during, and after (i) traffic measures entered into force at national level; (ii) curfew entered into force at national level; and (iii) quarantine entered into force (in Guayaquil, and whole Guayas province). We documented significant decrease in TSP emissions (PM2.5 and PM10) as compared to normal traffic proceeding in four-lane roads, in the cities of Quito, Guayaquil, and Cuenca. The most substantial drop in suspended particulate values $(96.47 \%$ decrease in PM2.5) relative to emissions observed prior to restricting traffic occurred in Cuenca.
\end{abstract}

Keywords: coronavirus, pollutant, particulate matter, quarantine, Guayas, Quito, Guayaquil, Cuenca, sustainable consumption, sustainability, PM2.5, PM10, sustainable production

\section{Introduction}

A new form of pneumonia, initially of unknown cause was detected in Wuhan (China) and reported to the WHO County Office in China on December 31, 2019.
Then, it was quickly discovered that it was caused by a novel coronavirus (WHO, 2020). On February 11, 2020, the name for the novel coronavirus COVID-19 was announced by WHO (WHO, 2020updates). Since then, the outbreak has spread to all continents, with over 880 
thousand, confirmed cases and over 44 thousand dead worldwide as of April 1, 2020 (WorldOmeter, 2020), also tracked by online interactive dashboards, using WHO, Chinese CDC, and Johns Hopkins University CSSE data updates; developed by Dong and co-workers (Dong et al., 2020). Researchers responded quickly by strengthening international research collaborations, an innovative example being published in Nature, on March 3, 2020, by Johansson and colleagues, who developed an open-source platform for rapid review of preprints related to emerging outbreaks, so called Outbreak Science Rapid PREreview (Johansson and Saderi, 2020). In addition to extensive scientific cooperation, demanding state and international-level decisions are taken to reduce COVID-19 spread. Such transport measures and curfew affect positively the environmental impact. On March 19, 2020 BBC announced that global $\mathrm{CO}_{2}$ emissions have dropped steeply; carbon monoxide emissions in New York have fallen by $50 \%$ over the past days (McGrath, 2020). Although, the number of COVID-19 related (mainly in medicine and drug discovery) papers is increasing at fast pace (more than 50 research publications on the topic by January 30 , 2020) (Stoye, 2020), scientific literature does not yet address the effects of precautionary measures on the environment. Therefore, studies that examine the effects of traffic restrictions on the environmental impact may contribute to rethink sustainability efforts that are of interest to the scientific community and attract public attention (Cohen, 2020). Ecuador is one of the first countries in South America to make hard national-level decisions regarding traffic limitations and curfew, since the first COVID-19 cases appeared in the region.

The country banned air traffic (both domestic and international) on March 16, 2020, as posted by France24, a decision made when the number of confirmed cases reached 37 (MSP, 2020). As of April 1, 2020, there have been 2,302 confirmed cases in the country according to data posted by governmental portal (Ministry of Health Ecuador, 2020). Nationwide measures to slow down COVID-19 spread are summarized chronologically in the Appendix. Considering the limited number of stations in the country that provide suspended particulates data to the public (Quito: 9; Guayaquil: 1; and Cuenca 3), established by the Ministry of Environment of Ecuador (Ministry of Environment, 2016), we consider as our duty to expand on these data by performing independent measurements.

Here we present Total Suspended Particulates (TSP) data for working hours (between 8:00 and 16:00 each day), which represents air pollution caused by traffic emissions in urban areas (Hsu et al., 2019) prior to, during, and after the above-mentioned emergency events. The most relevant regulations that affect traffic emissions are: (i) traffic restrictions at national level; (ii) curfew at national level; and (iii) quarantine (in Guayaquil). This data was acquired for the three most populated cities of Ecuador.

\section{Materials and Methods}

Temporary stations were setup between March 9 and March 13, 2020, as well as between March 16 and March 20, 2020 near four-lane roads of Ecuador's most densely inhabited cities: in Quito, with population of 2,644,145 (INEC, 2017) (GPS coordinates of the sampling: -0.202860 ; -78.503455); in Guayaquil, with population of 2,644,891 (INEC, 2017) (GPS coordinates of the sampling: -2.190911 ; -79.881079); and in Cuenca, with population of $1,186,025$ (INEC, 2010) (GPS coordinates of the sampling: -2.901375, -79.004688). Four representative sampling points of each city were chosen that reflect the air quality in the respective areas; two were considered the most vulnerable points (2-3 m away from direct traffic), exposed to direct air pollution, while the other two sampling points (controls) were not exposed to direct contamination from vehicle emissions (at $200 \mathrm{~m}$ distance from the main road) (Figure 1). Sampling points were chosen according to a prior study design (Rubio, 2019) in which vehicle count data were considered for selecting the sampling points; also, and the distance between control points and vulnerable points were discussed; authors recommended a distance between vulnerable points and control points to be of 100-200 m. TSP was measured in each city simultaneously, using High Volume Air Samplers (Model: 5300AFC, Tisch Environmental, Inc, USA), equipped with an aerodynamic diameter of less than 10 $\mu \mathrm{m}$ (for measuring PM10), and with another aerodynamic diameter of less than $2.5 \mu \mathrm{m}$ (for measuring PM2.5), using gravimetric method, as described din Code 40 of Federal Regulations, Code of Federal Regulation (SAE, 2017). Weight of filters were measured before and after $8 \mathrm{~h}$ long sampling, using a digital analytical balance (Model XPR, Mettler Toledo, USA). PM10 and PM2.5 concentrations are calculated from the total mass of particles divided by the volume of air sampled and is expressed in micrograms per cubic meter of air $\left(\mu \mathrm{g} / \mathrm{m}^{3}\right)$, according to Rojanoet et al., (2013), as shown in Equation 1:

$P M($ Concentration $)=\frac{V D(\mu g)}{T A\left(m^{3}\right)}$

Where,

WD represents weight difference $=$ filter mass $($ after $8 \mathrm{~h}$ measurement) - initial filter mass, and

TA is total volume of air analyzed over $8 \mathrm{~h}$. 

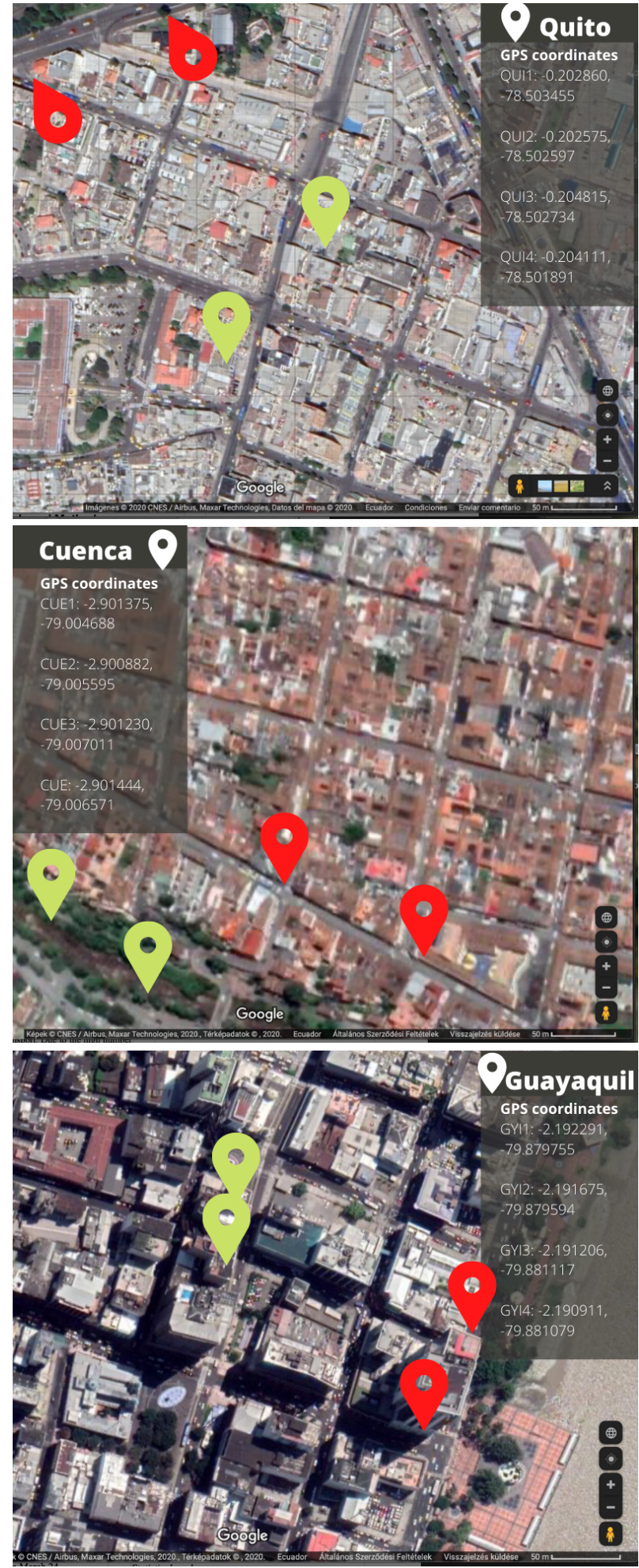

Figure 1. Map of sampling points with their GPS coordinates in Quito (top); Cuenca (middle); and Guayaquil (bottom). Red flags: most vulnerable points (2-3m distance from direct traffic): QUI1 and QUI2 in Quito; CUE1 and CUE2 in Cuenca; and GYI1 and GYI2 in Cuenca. Green flags: control points $(200 \mathrm{~m}$ distance from the main road in covered areas): QUI3 and QUI4 in Quito; CUE3 and CUE4 in Cuenca; and GYI3 and GYI4 in Guayaquil. Sampling period: March 9-20, 2020. For detailed sampling points see Supporting data.

\section{Statistical analysis}

One-way ANOVA model was used to reveal possible statistical differences (at significance level $\mathrm{p}<0.05$ ) between TSP parameters (PM10 and PM2.5) measured before and after entry into force of the traffic restrictions and curfew in Ecuador. For calculations SPSS (version 26) was employed.

\section{Results and discussion}

Significant decrease occurred in both PM10 and PM2.5 results, immediately after entry into force the state traffic measures (Table 1).

Table 1. Statistical differences between emitted suspended particulates measured before and after traffic measures

\begin{tabular}{llcc} 
Location & Particulates & \multicolumn{2}{c}{$\begin{array}{c}\text { Statistical } \\
\text { Differences }\end{array}$} \\
& & f-ratio & p-value \\
\hline Quito & PM10 & 1729.2 & $<.00001$ \\
& PM2.5 & 507.6 & $<.00001$ \\
Guayaquil & PM10 & 3062.3 & $<.00001$ \\
& PM2.5 & 894.4 & $<.00001$ \\
& PM10 & 776.7 & $<.00001$ \\
Cuenca & PM2.5 & 1065.4 & $<.00001$
\end{tabular}

While comparing the sampling sites, it can be stated that Guayaquil had the highest particulate matter values (PM10=30.5; and PM2.5=17.4) prior to the week of applied restrictions, as compared to Quito and Cuenca, so the decrease in suspended particulates is more significant in Guayaquil, than in the state capital (93.7 and $94.0 \%$ as compared to the week prior to traffic measures). Decrease in suspended particles is the most significant in Cuenca, where 95.9\%, and $96.5 \%$ drops are documented in PM10 and PM2.5 values.

\subsection{Quito}

Between March 9-13, 2020 (previous week of the traffic measures and curfew) PM10 values varied between 18.5 and $21.3 \mu \mathrm{g} / \mathrm{m}^{3}$, and PM2.5 values ranged from 9.27 to $12.3 \mu \mathrm{g} / \mathrm{m}^{3}$ at the vulnerable sampling points of Quito. On March 16, an 11.5\% increase in PM10 value, and $12.4 \%$ increase in PM2.5 value was observed relative to the average of the previous week, as a result of the announcement about first traffic restrictions on March 15; many car owners moved their vehicles on the last possible day before curfew). Between March 17-20, 
2020 we found a significant decrease in both PM10 (fratio $=1729.244 ; \mathrm{p}$-value $=<.00001)$, and PM2.5 values (f-ratio $=507.606 ; \mathrm{p}$-value is $<.00001$ ) as compared to data recorded over the previous week (March 9-13). PM10 and PM2.5 values varied between $2.03-4.2 \mu \mathrm{g} / \mathrm{m}^{3}$, and $1.37-2.78 \mu \mathrm{g} / \mathrm{m}^{3}$, after traffic measures were implemented. Both PM10 and PM2.5 values collected from vulnerable points decreased by $84.5 \%$, and $83.4 \%$, respectively, relative to the examined period before the measures, being of the same magnitude as their initial control values (see Supporting data).

\subsection{Guayaquil}

In Guayaquil the same pattern could be observed in
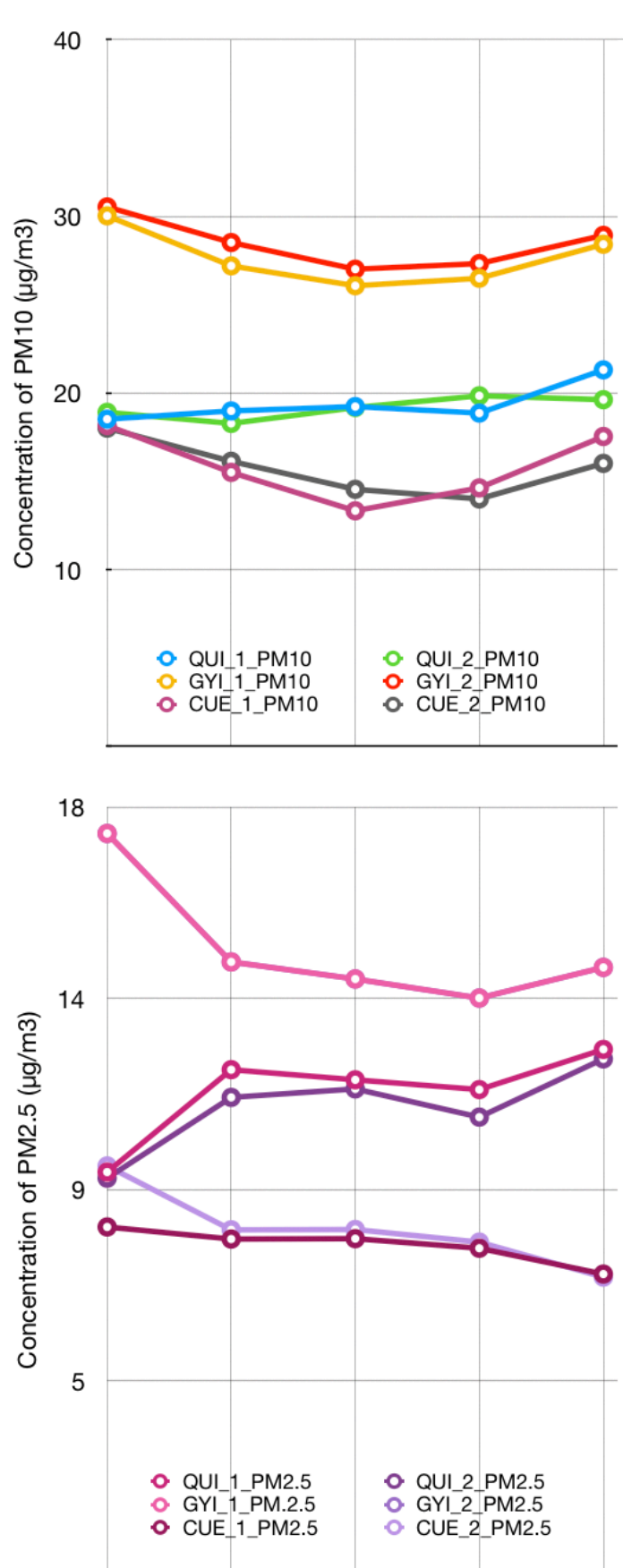

PM10 and PM2.5 values as for Quito: a steep increase in concentration of suspended particulates (Figure 1) can be observed on March 16, relative to previous week data, when PM10 varied between 26.07 and $30.53 \mu \mathrm{g} /$ $\mathrm{m}^{3}$; and PM2.5 from13.51 to $17.38 \mu \mathrm{g} / \mathrm{m}^{3}$. Perhaps for the same reason as in Quito, people took advantage of the remaining time before curfew, to move home their motor vehicles or to park them in a secure place. On the next day, March 17, we found a $93.7 \%$ decrease in PM10 and 94.0\% decrease in PM2.5. This decrease is steeper than in Quito, because of the higher emission values measured in Guayaquil prior to the applied traffic measures. Within the time period March 17-20, PM10 and PM2.5 values varied in the range of $1.52-2.03 \mu \mathrm{g} / \mathrm{m}^{3}$ and $0.86-1.01 \mu \mathrm{g} / \mathrm{m}^{3}$, respectively.

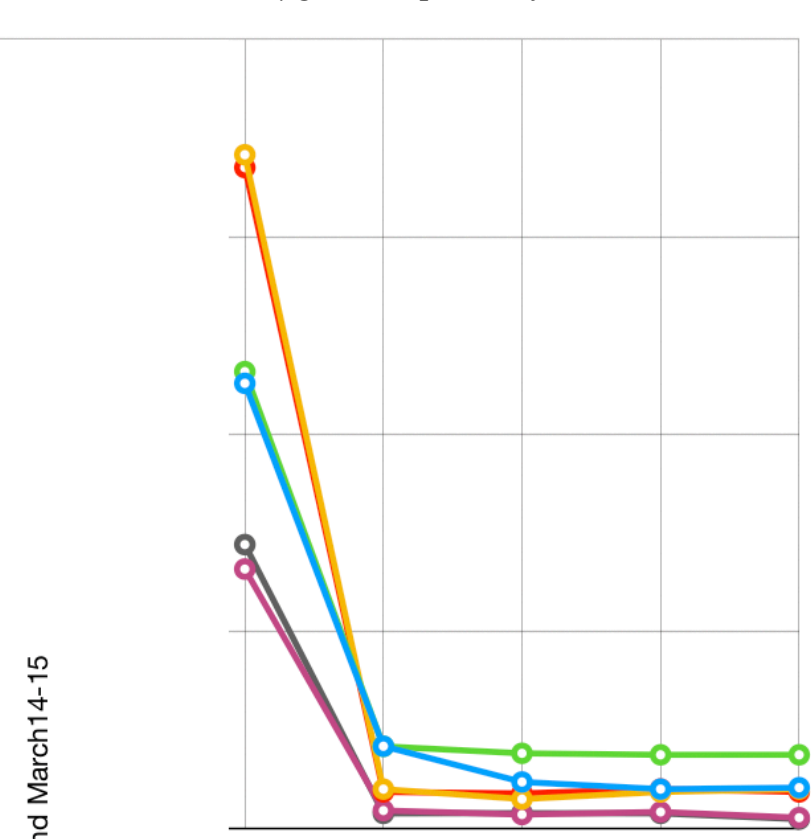

March 9 March 10 March 11 March 12 March 13 March 14 March 15 March 16 March 17 March 18 March 19 March 20

Figure 2. Changes in concentration of PM10 (top) and PM2.5 ( $\left.\mu \mathrm{g} / \mathrm{m}^{3}\right)$ (bottom) during periods

March9-16 (before traffic measures), and March17-20 (after traffic measures) at the vulnerable sampling points. Note: There is no data for weekend March14-15 because of the experiment was setup to measure suspended particulates in working days between 8:00-16:00 only; we were not aware of the forthcoming traffic measures and curfew at the week ending March 13 


\subsection{Cuenca}

Between March 9-13, 2020 the PM10 concentration varied between 13.2 and $18.2 \mu \mathrm{g} / \mathrm{m}^{3}$, and the PM2.5 values change between 6.57 and $9.55 \mu \mathrm{g} / \mathrm{m}^{3}$ at the vulnerable sampling points of Cuenca. On March 16 in Cuenca a different reaction to announcement can be observed in traffic compared to other two examined cities, there is a decrease in suspended particulates values since day March 16. The most significant decrease in suspended particulates relative to the week before traffic measures can be observed here (as compared to other two examined cities) with $95.9 \%$ fall in PM10, and 96.5\% fall in PM2.5 values (PM10: f-ratio value is 776.746, and p-value is $<.00001$; and PM2.5: $\mathrm{f}$ ratio value is 1065.398 , and the $p$-value is $<.00001)$. In period March 17-20 both PM10 and PM2.5 values constant (there is no significant change), vary between 0.51 and $0.76 \mu \mathrm{g} / \mathrm{m}^{3}$, and 0.14 and $0.36 \mu \mathrm{g} / \mathrm{m}^{3}$.

\section{Conclusions}

From obtained results the following conclusions can be drawn:

- Though sampling wwas conducted between 8:00 and 16:00 (working hours), in a period, when the half (as determined by plate numbers) of total amount of motor vehicles were permitted to run on the roads, and highways, consider that traffic was completely stopped in the examined areas, as revealed by the $91.3 \%$ decrease in concentration of suspended particles, relative to the week before the implementation of transportation restrictions. This finding documents that citizens follow the most restrictive guidance, and refrain from using their vehicles even over the allowed hours.

- Given that most Ecuadorian (both governmental and private) transport agencies use outdated diesel buses, these results may attract more attention on the number of suspended particulates released by the imperfect burn of fuels. As public transportation is completely suspended in the country since March 17, 2020, our results also reflect the beneficial effects of avoiding use of outdated diesel buses.

Limitation of the study: considering the limited number of temporary stations, where sampling was done, one cannot draw conclusions on emissions in the entire country. Our documented results allow to compare emission data in the examined areas for two time periods: before (March 9-13) and after (March 17-20) traffic measures being implemented in the country.

With this study we would like to inspire researchers for real-time communication of environmental load-related topics, and rethink sustainability efforts. COVID-19 outbreak can contribute to a transition of sustainable consumption and production of great interest of scientific and public attention (Cohen, 2020).

\section{Data availability}

Raw data (weight) for PM10 and PM2.5 and their concentrations along with sampling points coordinates and sampling dates are freely available under CC-BY 4.0 license:

Dama Research Center limited (2020): Supporting data for "Effect of transport measures and curfew against COVID-19 spread on air pollution (TSP) in Ecuador's three most populous cities". figshare. Dataset. https:// doi.org/10.6084/m9.figshare.12058005.v1

\section{References}

Dong, E.; Du, H.; Gardner, L. “An interactive web-based dashboard to track COVID-19 in real time". The Lancet Infectious Diseases 2020, doi:10.1016/ S1473-3099(20)30120-1

INEC National Institute of Statistics and Sensuses (https://www.ecuadorencifras.gob.ec/tras-las-cifras-dequito/)

INEC National Institute of Statistics and Sensuses (https://www.ecuadorencifras.gob.ec/wp-content/ descargas/Manu-lateral/Resultados-provinciales/ manabi.pdf)

Johansson, M.A.; Saderi, A. "Open peer-review platform for COVID-19 preprints." Nature 2020, 574, 29. doi: 10.1038/d41586-020-00613-4

Ministry of Environment, Ecuador, 2016 https:// www.ecuadorencifras.gob.ec/documentos/web-inec/ Sistema Estadistico Nacional/Comisiones/Ambiente/ Resoluciones/Res-CEEA-004-Cocentracion-promedioPM10-aire.pdf

Yung-Ho Hsu, Hsiao-Chi Chuang, Yu-Hsuan Lee, YuhFeng Lin, Yi-Jie Chen, Ta-Chih Hsiao, Mei-Yi Wu, HuiWen Chiu, Traffic-related particulate matter exposure induces nephrotoxicity in vitro and in vivo, Free Radical Biology and Medicine, Volume 135, 2019, Pages 235-244, ISSN 0891-5849, https://doi.org/10.1016/ j.freeradbiomed.2019.03.008.

\section{SAE Ecuadorian Accreditation Service,}

Stoye, E. "China coronavirus: how many papers have been published?" Nature 2020, doi: 10.1038/ d41586-020-00253-8

WHO. "WHO statement regarding cluster of pneumonia cases in Wuhan, China." Jan 9, 2020. https:// www.who.int/china/news/ detail/09-01-2020-who- 
statement-regarding- cluster-of-pneumonia-cases-inwuhan-china (accessed Feb 11, 2020).

\section{Software tools:}

Interactive Dashboard by Dong et al. (2020): https:// www.arcgis.com/apps/opsdashboard/index.html\#/ bda7594740fd40299423467b48e9ecf6

Outbreak Science Rapid PREreview (2020): https:// outbreaksci.prereview.org

\section{Posts:}

MINISTERIO DE SALUD PUBLICA DEL ECUADOR https://www.salud.gob.ec/se-fortalecen-acciones-deprevencion-por-covid-19-en-territorio/

MINISTERIO DE SALUD PUBLICA DEL ECUADOR https://www.salud.gob.ec/wp-content/uploads/2020/03/ Boletin-Covid-003 2020.pdf.pdf

France24 (https://www.france24.com/en/20200320-latinamerican-countries-step-up-coronavirus-restrictions-ascases-spread) Issued on: 20/03/2020 - 11:09; Modified: 20/03/2020 - 11:16.

McGrath. Coronavirus: Air pollution and $\mathrm{CO} 2$ fall rapidly as virus spreads. BBCnews Issued on: 19.03.2020 (https://www.bbc.com/news/scienceenvironment-51944780)

worldOmeter - COVID-19 CORONAVIRUS

PANDEMIC (https://www.worldometers.info/

coronavirus/, Accessed on March 26, 2020)

\section{APPENDIX}

- (March 8) National call for general prevention (MSPE, 2020).

- (March 13) Government announces national emergency after first confirmed dead ( https:// www.salud.gob.ec/se-fortalecen-acciones-deprevencion-por-covid-19-en-territorio/).

- (March 16) National traffic measures (France24 (https://www.france24.com/en/20200320-latinamerican-countries-step-up-coronavirus-restrictionsas-cases-spread) Issued on: 20/03/2020 - 11:09; Modified: 20/03/2020 - 11:16.) and ban of national and international flights was announced (France24).

- (March 16) First national traffic measure and curfew enter into force: usage of any vehicle (including city and intercity buses all around the country) and leaving homes are prohibited between 21:00 and 5:00. All boarders closed to Peru and Colombia.
- (March 17) Modified national traffic measures and curfew enter into force: usage of vehicles with license plates ending with even number is prohibited on Mondays, Wednesdays, Fridays, and Sundays; usage of vehicles with odd number ending license plate is prohibited on the rest of the days. Local or intercity buses are suspended. Due to the high number of confirmed cases in Guayas province, the entire province is isolated from the rest of the country; furthermore, no traffic to or from Guayaquil is allowed, all bridges are closed, the city is under quarantine. Leaving homes is prohibited from 16:00 until 05:00 next morning, all around the country.

- (March 22) First federal $24 \mathrm{~h}$ home quarantine announced from March 24. 